\title{
FAT EMBOLISM IN FOUR PATIENTS TREATED
}

\section{FOR FRACTURES}

\author{
Daniel C. AgBo, M.B., Ch.B. Glas. \\ Registrar in Orthopaedic Surgery, \\ Hull Royal Infirmary.
}

Fat embolism is well recognised to be an important though relatively infrequent complication of injuries of long bones. It has been shown that this is common in surgical or accidental damage to soft and skeletal tissues (Peltier, 1956), but that only in multiple fractures of bones is it severe enough to produce recognisable clinical symptoms and signs. The time when fat embolism was a post-mortem diagnosis has passed to one in which it is diagnosed early and in some cases successfully treated. Now, though it is recognised sarlier, the treatment is still largely empirical and symptomatic. Recorded below are the case histories of four patients recently seen and treated in the orthopædic unit.

\section{Case No. 1.}

J.H., a man aged 24 years, was knocked down by a car and admitted to hospital on January 13, 1961.

His injuries were:- a comminuted fracture of the mid-shaft of the right femur, an open comminuted fracture of the shaft of the right tibia, a fractured right fibula, a rupture of the anterior cruciate ligament of the right knee, and a fracture of the base of the terminal phalanx of the right hallux. His femur was reduced and immobilised on a splint on the day of admission. The following day an open reduction and screwing of the fractured right tibia was performed under a general anæsthetic. Fortyeight hours after admission he developed sweating, abdominal pain and petechial hæmorrhages in the skin of the pectoral region. His temperature rose to $101^{\circ} \mathrm{F}$ and remained so for two days. A provisional diagnosis of fat embolism was made. Abdominal examination revealed no evidence of injury to the viscera. In the urine fat droplets were recognised and the ether-soluble fat content was $8 \mathrm{mg} . / 100 \mathrm{ml}$. No count of blood chylomicrons was made. $\mathrm{Hb}$ $05 \%$. A chest X-ray showed fine mottling in the lung fields. These findings confirmed the diagnosis of pulmonary fat embolism. No specific treatment was instituted. All the symptoms cleared up within two days. He was discharged on May 12, 1961. Further out-patient treatment for his fractures was uneventful and he was finally discharged on the May 31, 1962.

\section{Case No. 2.}

W.I., a man aged 32 years, was knocked down by a car on May 18, 1962, and admitted to hospital suffering from an open fracture of the right tibia, a closed fracture of the left tibia and fibula, and a subtrochanteric femoral fracture. There was no history of head injury and he was fully conscious.

On the day of admission under a general anæsthetic his leg fractures were manipulated and immobilised in plaster and the subtrochanteric fracture treated by skeletal traction and a Thomas's splint. He recovered full consciousness. The next morning he became drowsy and sweated profusely. He developed petechial hæmorrhages in the skin at the base of the neck and upper part of the chest. Over a period of four to five hours he became deeply unconscious with decerebrate rigidity and incontinence of urine and fæces. He had a pyrexia of $102^{\circ}-106^{\circ} \mathrm{F}$ which lasted for one week. Chest and abdomen: no abnormal physical signs. Occasional Cheyne-Stokes respiration. A diagnosis of cerebral fat embolism was made. The only confirmatory neurological finding was a local infarct in the fundus of the left eye.

He was given anticoagulants, starting with heparin and continuing with dindevan within forty-eight hours. Sedation with sodium gardenal was necessary as the patient was very restless and was pulling down the splints used to immobilise his fractures. $\mathrm{He}$ was given penicillin and erythromycin prophylactically because of the open fractures he sustained. He was cooled with ice packs and by tepid sponging, and began to show some improvement in one week. He was no longer deeply comatosed and could respond to painful stimuli. He recovered full consciousness and mental faculties in three weeks. Control of micturition returned in seven weeks. The anticoagulant therapy was given for three weeks. He was discharged from the ward on December 7, 1962, for out-patient treatment. This out-patient supervision was uneventful and he was finally discharged on April 25, 1963, very fit and back to his former job as a machinist.

\section{Case No. 3.}

D.W., a man aged 22 years, who on September 29, 1962, while driving a motor cycle side-car combination ran into a post and was admitted to hospital with a comminuted fracture at the junction of the middle and lower thirds of the shaft of the right femur, an open dislocation of the left cuboid, an open fracture of the terminal phalanx of the left hallux, and multiple skin abrasions. He was shocked; there was no head injury.

He was given two pints of blood. Under a general anæsthetic given on the day of admission the fractures were manipulated and immobilized. He did not regain consciousness and twenty-four hours later developed decerebrate rigidity and petechial hæmorrhages in the skin of the base of his neck and upper chest. There was marked respiratory 
difficulty for which a tracheotomy was performed on October 1, 1962, three days after admission. Temps. $102^{\circ}-103^{\circ} \mathrm{F}$; the pulse rate rose to $160 / \mathrm{min}$. He became incontinent of urine and fæces. Investigations showed a segmental collapse of the lung and persistently low $\mathrm{Hb}$. of $62-67 \%$ in spite of the five more pints of blood given. An infarct was seen in the fundus of the left eye. A diagnosis of combined cerebral and pulmonary fat embolism was made.

He was given antibiotics and seven pints of blood over a period of two weeks. Prolonged cooling with ice-packs was necessary. The patient was unconscious for three weeks; his pyrexia lasted for nine days, incontinence of urine and fæces for nine weeks. He regained control of his bowel function before bladder function. He was discharged from the ward on the January 9, 1963, and his treatment continued as an out-patient. His fractured femur united and he returned to work. Mentally he remained dull though his concentration had improved and he had no headaches.

\section{Case No. 4.}

G.B., a man aged 22 years, was knocked off his bicycle by a car on November 2, 1962, and admitted to hospital suffering from a comminuted transverse fracture of the lower third of the shaft of the left femur and a comminuted fracture of the patella without separation. There was no history of head injury. Under a general anæsthetic his femur was manipulated and immobilised on a Thomas's splint. He recovered full consciousness after his anæsthetic.

The next day he became drowsy, confused and restless, passing into coma with incontinence of urine and fæces, and difficult respiration for which a tracheotomy was performed on November 4, 1962. He developed petechial hæmorrhages in the skin at the base of his neck and front of his chest, and the temperature reached $103^{\circ} \mathrm{F}$. on the second day after admission. The CNS signs were variable and included dilatation of the pupils to light and decerebrate rigidity. A clinical diagnosis of combined cerebral and pulmonary embolism was made.

Treatment consisted of the administration of penicillin and tetracycline, sedation with sodium gardenal and cooling the body with ice packs. He remained unconscious for a fortnight. There was hyperpyrexia for four days and pyrexia for another week. He became fully continent of urine and fæces in three weeks. He recovered normal mental faculties quickly after regaining consciousness. He was discharged from the ward on the 12th February, 1963, and his treatment continued as an out-patient. At the time of writing the patient's fractures had healed and he was back at work.

\section{Discussion}

These four patients all had multiple fractures involving long bones. Fat embolism occurred in all within forty-eight hours of injury. The symptoms and signs varied depending on whether the fat embolism was pulmonary, cerebral or combined. There is respiratory distress in both cerebral and pulmonary types of fat embolism. The signs in the cerebral type were variable and depended on the severity. But one clinical sign that was always present and could be regarded as pathognomonic of fat embolism was petechial hæmorrhages in the skin characteristically com fined to the base of the neck and the pectora regions (Hamilton, Bailey, 1960).

Aetiology. It is generally agreed that the bone marrow and blood lipids contribute to the formation of the fat embolism, the bone marrot supplying the bulk of the embolic fat. This wef proved by radioactive iodine-tagged fat studie in dogs, and by the finding of bone marro fragments in the lungs in cases of fatal embolisn? The fat globules from the bone marrow und pressure from the hæmatoma at the fracture site are carried to the lungs where most of the globules are arrested (Cobb and Hillman, 1961), but with increasing amounts of fat in the circulation some of the globules are further dispersed into th systemic circulation and thence into other vita structures like the brain, liver and kidney. The symptoms depend on the site at which most of the fat globules are arrested, being pulmonar cerebral or a combination of both.

A positive diagnosis of fat embolism ca $\dot{\bar{m}}_{\overrightarrow{1}}$ usually be made clinically. Laboratory findings are only ancillary and those reported to be helpf are:-

1. Radiograph of the chest.

2. The presence of fat droplets in venous blood and urine and sometimes in the saliva.

3. The blood chylomicron count.

It has been observed that the estimationo serum lipase and hæmoglobin help to indi when a patient is likely to develop fat embolis (Cobb and Hillman, 1961). For example, a rio in serum lipase and a fall in hæmoglobin occif in the early phase of symptoms. But as yet ne single simple laboratory procedure is know which when performed in a severely injured patient would warn of impending fat embolism

Treatment may be either preventive or de finitive. Under preventive treatment are such measures as the avoidance of unnecessaty manipulation of fractured limbs, correction of hæmorrhagic shock and the proper use of tourniquets, all of which are reputed to minimise the risk of fat embolism (Peltier, 1956; Whitson, 1951). But these measures even when meticulous carried out do not obviate the risk.

Restlessness, muscular spasm and decerebrate rigidity are treated by sedation. For respiratory distress oxygen has been given and in some cases tracheotomy and the use of a mechanicy respirator have been necessary. When the temperature-regulating mechanism has been deranged, with hyperpyrexia, cooling with ite packs is required (Newman, 1962). In two our cases, 2 and 3 , we consider that this measuf saved the patient's life.

But the most-needed definitive treatment is one which would deal directly with the fat globule in the circulation. The use of intravenous sodium 
desoxycholate $(10 \mathrm{ml}$. of $20 \%$ solution) which increases the emulsifying power of the blood and so reduces the size of circulating fat globules is limited because in larger doses it produces hæmolysis. Next, anticoagulant therapy has been advocated (Cobb and Hillman, 1961). Heparin is supposed to alter the lipoprotein density and would also prevent thrombosis if an occlusion did occur from the fat globules. From this small series, the impression gathered was that severe cases treated with anticoagulants recovered from the effects of fat embolism sooner than those treated without.

The treatment of these four cases has been discussed briefly; they are presented because they recovered in spite of prolonged unconsciousness, hyperpyrexia, respiratory and neurological involvement. It is also apparent that at the moment, beyond reduction of the hyperpyrexia, the quietening of the restlessness, and provision of a free airway for the patient with respiratory distress there is little to be done except to give anticoagulants, which did not interfere with fracture healing.
I wish to express my gratitude to Mr. R. C. Tatham and Mr. C. R. Berkin, Orthopædic Surgeons, for permission to publish these case histories of patients treated under their care and for the helpful advice given in the presentation of this article.

\section{REFERENCES}

Bailey, H. (1960): Signs and Symptoms in Clinical Surgery. p. 793. Bristol: John Wright.

BAILEY, H., and LOVE, M. (1960): A Short Practice of Surgery. p. 96, 11th edition. London: H. K. Lewis. CoBb, C. H. and Hillman, J. W. (1961): 'Fat Embolism' Instructional Course Lectures, 1961 (Fred Reynolds) p. 122. American Academy of Orthopædic Surgeons.

GARDNER, A. M. N. and HARRISON, M. H. M. (1957): Report of the Treatment of Fat Embolism with Heparin, J. Bone Jt. Surg., 39B, 538.

KeY, J. A. and CoNwell, H. E. (1956): Management of Fractures, Dislocations and Sprains. 6th edition. p. 125. London: Henry Kimpton.

Newman, P. H. (1948): Clinical Diagnosis of Fat Embolism. J. Bone Jt. Surg., 30B, 290.

Newman, P. H. (1962): Fat Embolism. ibid, 44B, 761. Peltier, L. F. (1956): Fat Embolism-The Prophylactic Value of a Tournique, ibid, 38A, 835.

Whitson, R. O. (1951): Critique of Fat Embolism, ibid, 33A, 447.

\section{INTRACTABLE PRURITUS DUE TO HEPATIC CIRRHOSIS RELIEVED BY CHOLESTYRAMINE}

\author{
Kalman KeCZKes*, M.B.Glas., M.R.C.P.E. \\ Registrar \\ Alan Lyell, M.D.Camb., F.R.C.P.E. \\ Physician-in-Charge
}

Department of Dermatology, Glasgow Royal Infirmary.
PruRitus due to liver disease is almost always due to biliary obstruction with associated retention of bile salts and other ingredients of the bile. The pruritus is always troublesome and its control is notoriously unsatisfactory. We report a case of hepatic cirrhosis whose pruritus was successfully relieved by cholestyramine.

\section{Case Report}

A married woman aged 47 attended the dermatological out-patient department on December 5th, 1962, complaining of severe generalised pruritus and tiredness for the last 5 years. At the beginning of her illness she had had bouts of violent sickness and vomiting at intervals of 6 to 7 months, but this had not troubled her much lately, although she had to avoid fried food because it made her feel sick.

She had scarlet fever in childhood. She had lived in N. Rhodesia from 1940 to 1946 where she suffered from enteritis and several mild attacks of malaria, from which she had been free since her return.

$$
\text { * Present Address: }
$$

Department of Dermatology, Dundee Royal Infirmary.
She was seen elsewhere for her skin complaint in 1960 and was put on Liq. Arsenicalis (Fowler's solution), which controlled her itching for the first time. She was kept on arsenic for about a year with reasonable control of pruritus, and thereafter this regime was stopped. Soon afterwards the pruritus returned, no other means could be found to control it, and it eventually got so bad that it interfered seriously with her sleep.

Physical examination revealed a thin, anxious looking woman with an earthy discolouration of the whole skin. There were numerous scratch marks on the body and limbs and some scattered superficial scars on the trunk and upper limbs. The provisional diagnosis was dermatitis herpetiformis and she was put on Dapsone $100 \mathrm{mg}$. b.d., which failed to control the pruritus. She was accordingly admitted on the 23rd April, 1963 for further investigation.

In hospital she was noticed to have pale coloured stools and dark urine occasionally, and her liver was palpable three finger breadths below the costal margin.

Investigations: $\mathrm{Hb} .11 \mathrm{gg} / 100 \mathrm{ml}$. PCV $35 \% \mathrm{MCHC}$ $32 \%$. The blood film was normal and Heinz bodies could not be found. Thrombotest $100 \%$. ESR 37 